\title{
OgUAA JOURNAL OF SOCIAL SCIENCES
}

VOLUME 9 ISSUE 1, JUNE 2020 


\title{
FACTORS INFLUENCING HOUSEHOLD ENERGY CHOICES IN THE KUMASI METROPOLITAN AREA OF GHANA
}

\author{
Emmanuel Adjei-Danso', Emmanuel YamoahTenkorang ${ }^{2}$, Patrick Osei-Kufuor ${ }^{3}$ \\ ${ }^{1}$ Ghana Mineworkers Union of Trades Union Congress, Accra \\ ${ }^{2}$ Department of Environment, Governance and Sustainable Development, School for Development Studies, \\ University of Cape Coast, Ghana \\ ${ }^{3}$ Department of Peace Studies, School for Development Studies, University of Cape Coast, Ghana
}

\begin{abstract}
Reforms in the energy sector are expected to bring about essential efficiency gains, which could result in energy diversification and welfare improvements among households. However, there are other unintended social and environmental consequences associated with the process. One significant social concern is the likely impact on how low-income families access new energy. The study used a cross-sectional design to undertake a comparative analysis of domestic energy choices. Data was collected from 405 households' decision makers. An interview schedule and a guide were used for the data collection. The results showed that modern fuels are by far the most predominant source of energy for high and medium class residential households in Kumasi. However, residents in low-class areas preferred to use biomass fuel as their primary energy choice. Contextual variations revealed that
\end{abstract}

\section{Introduction}

Energy is an essential component of every household's consumption basket. Energy sources range from traditional biomass fuels such as fuelwood and charcoal to modern fuel types like Liquefied Petroleum Gas (LPG) and electricity. Recent global concerns about climate change, environmental degradation, and indoor air pollution, however, have implications on the options of energy sources available to households. According to Kaale (1990), the various types of energy sources present different effects on climate change, environmental degradation, and indoor air pollution. The residential sector is a potent source of greenhouse emissions, with direct Carbon Dioxide $\left(\mathrm{CO}_{2}\right)$ emissions from primary fuel consumption constituting $(18 \%)$ of global $\mathrm{CO}_{2}$ emissions in 2008 (OECD \& IEA, 2010; WHO, 2010). According to the World Health Organisation (WHO), household energy systems in developing economies contribute relatively more to climate change than in advanced economies since traditional stoves predominantly used in the former generate high concentration of methane and black carbon resulting from incomplete combustion of general factors such as affordability and accessibility of energy source were exogenous determinants of energy choice. The findings of the study also lend support to the energy ladder hypothesis that household income is a significant determinant of household energy choice. Further, social and demographic factors are critical determinants of cooking fuel type in residential zones. The study recommends the promotion of modern fuels through developing dependable energy distribution systems, and public education campaigns by the Energy Commission of Ghana.

Keywords: Energy ladder, Energy choice, Biomass fuel, Households

biomass and other solid fuels (WHO, 2010).

It is worth mentioning that various countries, in the effort to provide energy sources for their citizenry, have had to consider several factors affecting the demand and supply of these sources. Some of the factors considered include affordability, environmental effects, accessibility, and international obligations under different treaties. Therefore, states have had to strategize to maximize their utility under these circumstances. Some of these strategies include development policies, energy policies and procedures (Ministry of Energy, 2010). Energy is critical to economic development and poverty reduction. Access to clean and affordable energy in Africa is an essential aspect of the fight against environmental degradation. Energy access, both directly and indirectly, contributes to achieving Sustainable Development Goals (SDGs) 1 and 7 as it plays an essential role in the ability of a household to overcome poverty and build resilience (Dutta, 2005; Kanagawa \& Nakata, 2007; IEA, 2010). International Energy Agency (2010) defines energy poverty as: "The lack of access to sustainable modern energy services and products." Implied in 
the definition, "access to energy services" requires a source of fuel or electricity, but also that the energy is available when needed and a household can afford both the power and energy-consuming technology that provides a service. Thus, energy poverty is the lack of access to suitable traditional (firewood, chips, dung cakes, etc.) and modern energy services and products (kerosene, liquefied petroleum, gas, etc.).

Ghana has had its fair share of considerations and strategies for the provision of energy to attain development. The development objectives and strategy for Ghana's energy sector in the 1990s were enshrined in the Government's 'Vision 2020,' and these were to increase the reach of energy resources to all sections of the country to facilitate their socio-economic improvements, especially the majority rural people.

The energy sector is sub-divided to address critical issues such as firewood consumption, petroleum, and electricity. In this regard, the industry has been categorized as; Firewood, Electricity and Petroleum sub-sectors. Since the production and supply of firewood in Ghana was already private sector-driven, reforms in the sector were expected to focus on initiating and supporting appropriate regulatory mechanisms that would ensure the sustainability of the division (Ministry of Energy, 2010). Key areas of this reform included; rationalization of the fiscal framework for firewood exploitation, transportation and distribution to create economic incentives for the better management of firewood production and supply.

Structural reforms in the power sector were initiated in 1995. The government saw the improvements as the most productive response to the many problems in the power sector. The industry focused on critical areas such as effecting structural changes that would move the power sector away from the existing monopolistic structure towards a more decentralized one to expose the utilities to competition in both generation and distribution of electricity and also to enhance transparency in the regulation of the power sector.

Unlike the electricity sub-sector, limited attempts were made to reform the petroleum subsector. So far, two main reform initiatives were proposed for the sub-sector: deregulation of the distribution and the liberalization of the pricing of petroleum products, both of which were intended to enhance aggressive marketing and pricing of petroleum products at the pump (ESMAP, 2003). Deregulation of the distribution has still not materialized.
It has become essential as a country to prioritize the use of cleaner/modern fuel, especially when it is undoubtedly clear that Ghana is an energy-deficient country with many households relying on traditional fuels as their primary source of energy. This is in contrast with the efforts made by the government to get families to switch from using inefficient fuels to efficient ones (Asante, Addoquaye-Tagoe \& Clottey, 2006). In Ghana, the bulk of energy consumption is based on fuelwood, and $90 \%$ is obtained directly from natural forests. The use of solid fuels for cooking in households in Ghana is estimated to be $73 \%$ (Obeng, Mensah, Ashiagbor, Boahen, \& Sweeney, 2017). The use of solid fuels in urban areas is generally lower than in rural areas because of the availability of LPG, although in the Kumasi Metropolitan Area, fuelwood usage is slightly higher than LPG. Kumasi, the capital of the Ashanti Region, is one of the fastest growing metropolises in Ghana. The initial attempt to classify housing in Kumasi into distinctive sectors was undertaken by Tipple (1984). This report, in essence, situates the four broad-sectorclassifications in the context of Tipple's (1984) work. It is made up of four residential zones. These are high-density low-class area, high-density medium class area, medium density medium class area and low-density high-class area ${ }^{1}$. The type of energy source available in the metropolis includes wood, charcoal, kerosene, LPG, and electricity.

Despite the varied energy choices available in the Metropolis, households still preferred to use biomass fuel (charcoal) relative to modern and cleaner energy alternatives. GLSS (2010) revealed that in Kumasi65.1 percent of household decision makers used the traditional fuel (fuelwood, charcoal, and kerosene). Disaggregation of the results also showed that 50.2 percent of households opted for charcoal other than any fuel choice. Less than 35 percent of households in the Metropolis resorted to the use of LPG as their primary source of fuel for cooking. Despite the efforts made by the Government to promote the use of modern fuels, it is still unclear why households preferred to use biomass fuel other than modern fuels in the second most urbanized area in Ghana.

An effect of this traditional energy consumption is a challenge in achieving affordable and cleaner energy (SDG7). There was, therefore, the need to carry out a study on the factors that influenced household fuel choice, fuel substitution and wood fuel expenditures in the metropolis. Although studies have been done in relation to how a particular energy choice impact the environment,

\footnotetext{
${ }^{1}$ Information on Tiplple's initial classification can be found at http://dx.doi.org/10.1080/00320718408711726
} 
the problem of what is the cause of household energy choice and switching was still a gap.

\section{Review of related literature}

The literature is replete with research that seeks to understand households' energy transition from one type of fuel to another, more efficient and cleaner energy form. One leading theory that is utilized by researchers to explain this switch among households is the household energy transition model.

The household energy transition theory draws on Durkheim's (1984) idea to explore the relationship between social change (such as improved communication and transportation, monetization, and population density) and the division of labour in society. This theory suggests a relationship between social organization and the fundamental ways in which humans use their environment. The method further explains the energy transition through a system of fuel switching from primary fuels, such as wood fuels and crop residue, to modern fuels such as bio-ethanol, LPG or electricity and thereby eliminates the drudgery of looking for and transporting the traditional fuels home for use. Besides, there is more time freed from these laborious activities which are applied to other productive ventures (Singh, Nouhou, \& Sokona, 2015).

Barnes, Openshaw, Smith and van der Plas (1993) note that wood fuels have become expensive to households, both in terms of cash or collection time. Societies also bear the consequences in inefficient energy use, deforestation, harm to health and the environment. Modern fuels minimize these harmful effects and should be promoted by states.

Studies focusing on energy transition often identify factors such as income, access to electricity, household size, and scarcity of forest resources as key determinants for fuel switching. Campbell et al. (2003) establish that higher income households in urban areas tend to transition to modern cooking fuel sources such as kerosene and electricity, as opposed to using wood fuels as their primary energy source like the majority of lower-income residents. Similarly, Ouedraogo (2006) noted that as households' income increases, households' firewood use systematically decreases.

Forest resource scarcity also leads to fuel switching, as households may no longer have access to nearby resources for firewood collection. Therefore, the increase of firewood collection time is also a determinant for fuel switching (Heltberg, Arndt \& Sekhar, 2000). According to Campbell et al., (2003), Davis (1998) and Ouedraogo (2006), access to electricity also plays a vital role in shifting the reliance on traditional fuels to modern ones.

Three main models have been formulated and structure the discourse of energy transition theory: the energy ladder, leapfrogging model and the multiple fuel use approaches.

The 'energy ladder.'

The 'energy ladder' is still the dominant approach in the transition theory since its development in the 1980s. Since then it has been supported with various studies and widely utilized to explain different behaviours (see Barnes \& Floor, 1996; Leach, 1992; Akabah, 1990; Hosier \& Dowd, 1987). The 'energy ladder' posits that there is a positive relationship between socioeconomic level and modern fuel uptake; that an increased income is positively correlated with the adoption of and transition to more efficient, cleaner, and costlier energy sources.

The principal notion underlying this concept is that households face a range of energy supply choices, which can be ordered from least to most technologically sophisticated. The main argument of the model is that as income increases, households adopt more modern cooking fuels. Thus, there is a linear process in which households cease to use traditional biomass fuels and take current alternatives as their affluence level increases (Macht, Axinn, \& Ghimire, 2007; Barnes \& Floor, 1996; Leach, 1992). The model proposes income as a determinant for fuel choice, and thus the rationale for transitioning up the energy ladder. The model implies a neoclassical consumer chooses rationally, the best available and affordable fuel to maximize utility. The consumer is presumed to have subjective ranked preferences for the different fuels ordered by their physical characteristics such as cleanliness, ease of use, cooking speed and efficiency as well as fuel costs (Reddy \& Reddy, 1994; Hosier \& Kipyonda, 1993; Leach, 1992; Akabah, 1990).

Mostly there are three phases in the energy ladder; the first phase is defined as a universal reliance on biomass in the form of wood, dung and agricultural residues. The second phase is characterized by a fuel switch to transitional fuels such as kerosene and coal. The third and final phase is the adoption of modern cooking fuels such as LPG, natural gas, electricity or other 'clean' sources of energy (Heltberg, 2004).

Various studies have critiqued the energy ladder for focusing on income solely as the explanatory variable and its implicit assumption 
of the rational consumer moving from one fuel linearly in an upward trend to the other (Hiemstravan der Horst \& Hovorka, 2008). Jebaraji and Iniyan (2006) are of the view that the energy ladder model focuses too rigidly on economic processes such as determinants of fuel choice with no concern for specific social, cultural and behavioural processes like traditional foods and how they are prepared, which influence energy choice. According to the energy ladder hypothesis, firewood is seen as an inferior economic good, often associated with a necessity rather than a choice. It can be seen as "fuel of the poor" (Leach, 1992). However, Hiemstra-van der Horst and Hovorka (2008) illustrate that in Maun, Botswana, firewood is not restricted to low-income strata. It is widely used by all income groups, due to consumer preferences and lifestyle considerations, like the type of food preferred (Agbonlahor, 2015), as opposed to income restrictiveness.

\section{The leapfrogging model}

The leapfrogging model, on the other hand, suggests that developing countries may learn from the experiences of developed nations, and tunnel through technological generations to adopt most recent technologies and avoid various environmentally degrading stages of techniques (McGranahan, 2007; Munasinghe, 1999). Doing so, it is suggested that developing countries can avoid repeating the environmentally destructive experience of today's developed world and build for a more sustainable future. For household energy development, leapfrogging proposes the introduction of modern sources of energy to households in a fast and cost-effective manner, as a means to counter environmental degradation associated with traditional energy sources (Anenberg, 2012).

This 'north-south' transfer of technology is often achieved through a system of stove distribution programmes, stove subsidies, and promotional campaigns. Much emphasis is placed on making the technology affordable for the poor to use in developing countries who mostly use biomass fuels (Anenberg, 2012). It is therefore proposed that the energy ladder model be replaced with a two-step approach from traditional fuels, straight to advanced energy sources. This will thus avoid some of the environmental and health problems associated with transitional fuels such as coal and kerosene.

In Leapfrogging, the introduction of foreign developed technologies is proposed because of the belief that many developing countries have constrained capabilities to create and disseminate local innovations. Murphy (2001) categorises such limitations as being technical, organisational and institutional. Technically, technologies can be challenging to manufacture cost efficiently, safely and durably. Occasionally, countries may lack the resources to disseminate technologies effectively. There may often be an aid dependency for such initiatives to occur. Institutionally, technological adoption may be constrained by social structures in place. Gender-based roles and community resource allocation traditions may, for example, allocate a low priority for improved cooking technologies, which primarily affect women (Murphy, 2001). It is therefore believed that by creating technologies abroad, one can bypass such constraints.

The leapfrogging model is considered as a misconception because, in the majority of instances, modern cooking technologies are developed abroad and disseminated in developing countries (Murphy, 2001). Although such techniques are popular in some parts of the world, they often fall short of meeting specific social, cultural, and economic conditions that exist in local community contexts. Technological absorption, therefore, does not occur because of the absence of proper social, cultural, political, and economic institutions to support adoption, dissemination, and appropriate contextual innovation.

\section{The multiple fuel use approach}

Masera and Navia (1997) are the leading proponents of the multiple fuel use approach. They used the method to investigate the energy patterns in rural Mexican households. In a followup study, Masera, Saatkamp, and Kammen (2000) elaborated this concept as a critic and an alternative to the energy ladder. The theory suggests that most households in developing countries do not apply the single-fuel substitution and linear transition indicated by the energy ladder but instead employ a variety of fuels simultaneously, potentially including all levels reported on the energy ladder (e.g., Arnold et al., 2006; Martins, 2005; Campbell et al., 2003; Masera \& Navia, 1997; Milukas, 1993).

The underlying argument of this model is that an income level increase may not lead to household energy switch upwards the 'energy ladder' as they will still keep lower-level fuels and use them simultaneously or as a supplement (Masera et al., 2000). In a study in rural households in Haryana, India, that had been using LPG for many years, households still consumed agricultural waste and firewood as primary cooking fuel due to financial limitations (Joon et al., 2009). Similar observations have been made by Davis (1998) in 
South Africa or PREDAS (2009) in many Sahelian countries. In some instances, fuel availability and access are observed as main drivers (Campbell et al., 2003; Davis 1998). In effect, households follow a fuel diversification strategy to ensure a reliable energy supply (Pachauri, 2011).

The majority of researchers have concluded that instead of the single-fuel energy ladder, a multiple fuel transition is experienced with households moving up and down because of their economic possibilities (Campbell et al., 2003; Davis, 1998; Hosier \& Kipyonda, 1993; Leach, 1992; Martins, 2005).

\section{Methodology}

The study used a cross-sectional mixed methods design (Bowling, 2009) to investigate household energy transition choices. The crosssectional mixed methods is well suited for examining studies that cross different sections by combining quantitative and qualitative approaches to make inferences about a population of interest (universe) at one point in time (Prentice et al., 2011).

The multi-stage sampling approach was considered appropriate for the study because Sampling is carried out sequentially across three hierarchical levels before reaching the unit of analysis (Cochran, 1977). First, the KMA was divided into four quadrants (North, East, West,
South) and then the communities in each quadrant were stratified into four residential classifications namely: High-Density Low-Class Area (HDLA), High Density Medium-Class Area (HDMA), Medium Density Medium Class Area (MDMA) and Low-Density High-Class Area (LDHA). Stratification reduces the likelihood that people within the same income threshold and using the same energy source will be left out of the sample. The assumption underlying this classification is that energy choice decision in the household is unique for each residential zone since the economic activities and the basic human activities that take place differ from one residential area to another.

Secondly, a community each from the residential zones was randomly selected in each quadrant. Thus, in each quadrant, four communities were chosen bringing the total number of cities to 15 as the second quadrant had no LDHA zone. This was to ensure a fair representation of residential zones across the four quadrants. The residential description in each quadrant was of interest because the study emphasizes the relationship between the location of a residential community, access to fuel and how access to energy influences energy choice decisions within the neighbourhood. Figures 1 and 2 illustrate the classifications.

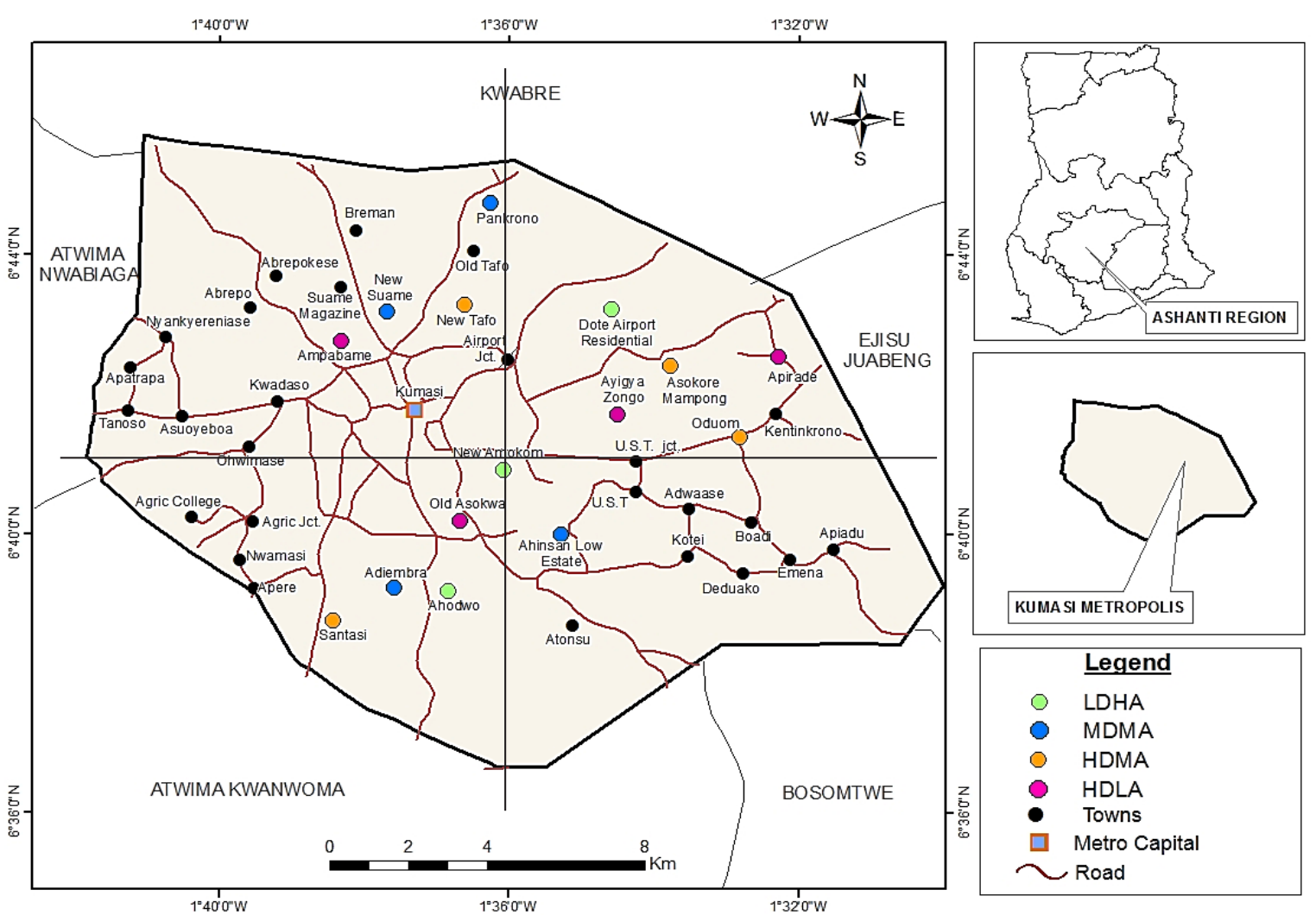

Source: Cartographic Unit, University of Cape Coast, 2015 
Table 1: Summary of communities sampled

\begin{tabular}{|c|c|c|c|c|}
\hline \multicolumn{5}{|c|}{ Residential zones and Communities } \\
\hline Quadrants & LDHA & MDMA & HDMA & HDLA \\
\hline $1 \mathrm{st}$ & Dote, Airport & New Suame & New Tafo & Ampabame \\
\hline $2^{\text {nd }}$ & & Pankrono & Asokore Mampong & Aparade \\
\hline $3^{\text {rd }}$ & Ahodwo & Adiembra & Santasi & Old Asokwa \\
\hline $4^{\text {th }}$ & New Amakom & Ahinsan estate & Oduom & Ayiga Zongo \\
\hline
\end{tabular}

Source: Fieldwork, 2015

With a population of 2,187,772 in 2016 (KMA, 2016) and an average household size of 3.8 in 2010 (GSS, 2010), the total number of households in Kumasi was projected to be $2,187,772 / 3.8=575,729.48$ households. In determining the representative sample size of families from a population of 575,729.48, Krejcie and Morgan (1970) suggested a sample size of 384. However because a sampling frame for the 15 communities was not available, a nonproportionate to size sampling of 27 households in each city was done. This brought the total households sampled to 405. In the absence of the list of all families in each selected community, the study used a systematic sampling technique to select the twenty-seven household respondents from each city.

At the community level, the general center of the community was determined as the starting point for sampling. By rolling a dice, the number $\mathrm{n}$ between one and six show was used as the sampling factor. Moving along the four cardinal axes, every nth house was selected, and a household randomly chosen from it until the 27th household was reached to constitute the sample. Although the random-walk sampling principle did face some critiques concerning its randomness and validity as it is often combined with specific quotas, the form applied within this research without quota sampling is legitimate (HoffmeyerZlotnik, 2003; UN, 2005). In all, a total of four hundred and five (405) household energy decision makers was selected from the fifteen communities from the four residential zones.

Purposive sampling was used to select the key informants for the study. The key informants were from the Forestry Commission, Forest Services Division of the Forestry Commission and the Energy Commission.

The interview guide and the interview schedule were the two main instruments used to gather information for the study. The interview guide was the instrument used in collecting data from the key informants while the interview schedule was used to solicit responses from household decision makers on energy choice.

\section{Data analysis and estimation technique}

As discussed in the literature, households ascend a largely hierarchical ladder of fuel types that are orderly ranked. This suggests ordinal preferences among the fuel types in terms of efficiency, cleanliness and affordability and thus, consistent with an ordered choice framework. The outcome variable was dichotomous and assumed a nominal scale of measure. The multinomial logit is used for studies with categorical dependent variables which are measured on the nominal scale of measure.

To answer the objective of analysing factors influencing household main choice of cooking fuel, the study employed the multinomial logit model. Theoretically, household fuel choices are supported by rational considerations. The household selects fuel choice between a set of mutually exclusive and highly differentiated cooking fuels such as Electricity, LPG, charcoal, firewood, and kerosene (alternative fuels). In making this selection, the household is assumed to act so as to maximise utility (McFadden, 1974). The household fuel choice is determined by economic and non-economic factors. The McFadden's model can be expressed as follows: $\mathrm{Z} \_\mathrm{ij}=\alpha \mathrm{w} \_\mathrm{i}+\mathrm{y} \_\mathrm{ij}$,

$\mathrm{j}=0,1,2,3, \mathrm{k} ; \mathrm{i}=1, \ldots \ldots ., \mathrm{N}$

where:

$\mathrm{Z} \_\mathrm{ij}$ is the benefit associated with using a particular fuel, and is assumed to be a linear function of a set of observed variables, with i indexing individuals or households and $\mathrm{j}$ (where $\mathrm{j}=5$ ) indexing mutually exclusive fuel alternatives, namely; Electricity, LPG, charcoal, firewood, and kerosene; $\alpha$ is a vector of coefficients to be estimated; $\mathrm{w}$ is a set of economic and social variables; and 
is a disturbance term that is associated with individual $\mathrm{i}$ and fuel $\mathrm{j}$.

If the household makes choice $\mathrm{j}$ in particular, then we assume that $Z_{-} \mathrm{ij}$ is the maximum among the five-fuel source, that is chosen if $Z_{-}$ij (alternative $\mathrm{k}) \square \square \mathrm{j} \square \mathrm{k}$. The observed energy choice is defined as a vector $Z_{-} i j=\left[Z_{-} i j\right]$ of five dummy variables taking value 1 if the household's choice falls on the $\mathrm{j}^{\wedge}$ th alternative, and value 0 otherwise. The probability that $j$ is included in $i^{\text {' }} \mathrm{s}$ choice set is $P_{-} i\left(Z^{*}>1\right)$. Where $Z^{*}$ is the number of energy choices in the study.

This fuel choice probability can be expressed as:

$P_{i}\left(Z_{i}=\mathrm{j}\right) \frac{\exp \left(\alpha_{i j} w_{i}\right)}{\sum_{\mathrm{j}=0}^{\mathrm{m}} \exp \left(\alpha_{i j} w_{i}\right)}$, and $\mathrm{j}=0,1,2,3,4,5$

To investigate the factors that affect household fuel substitution from traditional fuel and transitional fuels to modern fuels, the study looked at the characteristics of various fuels that were key in influencing household decisions. These fuels include: biomass residues, grass, firewood, charcoal, kerosene, biogas, LPG and electricity for both rural and urban areas. The multinomial

\section{Characteristics of respondents}

The components of the respondents are presented in Table 2. logit model was employed. First, this model takes into account the possibility of multiple fuel use by grouping these fuels into three fuel categories, traditional, transitional and modern fuels. Second, the model shows substitution effects (cross effects) where changes in characteristics of a particular fuel category are investigated and how they influence the changes in probabilities of other fuel categories. Equation (3.2) is used to examine the factors affecting fuel substitution, where $\mathrm{j}$ is the fuel categories $(j=3)$. In the case of modern fuels, the study looked at the changes in characteristics of modern fuels and how this change affects choice and substitution of traditional and transitional fuel categories.

\section{Results and discussion}

The results are discussed along with the lines of the characteristics of respondents, key factors that influenced household cooking energy, patterns, and the role income played in household energy choice decisions within the Kumasi Metropolitan Area.

Table 2: Demographic Characteristics of respondents

\begin{tabular}{|c|c|c|}
\hline \multirow[t]{2}{*}{ Background Characteristics } & \multirow{2}{*}{$\frac{\text { Frequency }}{\mathbf{N}}$} & Percent \\
\hline & & $\%$ \\
\hline \multicolumn{3}{|l|}{ Sex } \\
\hline Female & 392 & 97 \\
\hline Male & 13 & 03 \\
\hline Total & 405 & 100 \\
\hline \multicolumn{3}{|l|}{ Age range (years) } \\
\hline Below 30 & 68 & 16.8 \\
\hline $31-40$ & 90 & 22.2 \\
\hline $41-50$ & 179 & 44.2 \\
\hline $51-60$ & 61 & 15.1 \\
\hline Above 60 & 7 & 1.7 \\
\hline Total & 405 & 100 \\
\hline \multicolumn{3}{|l|}{ Occupation } \\
\hline Civil servant & 161 & 39.8 \\
\hline Self-employed & 201 & 49.6 \\
\hline Unemployed & 43 & 10.6 \\
\hline Total & 405 & 100 \\
\hline \multicolumn{3}{|l|}{ Educational level } \\
\hline No education & 84 & 20.7 \\
\hline Primary & 37 & 9.1 \\
\hline Secondary & 98 & 24.2 \\
\hline Tertiary & 186 & 45.9 \\
\hline Total & 405 & 100 \\
\hline
\end{tabular}


Majority of the respondents were females (97\%). The most frequent age category of the respondents was $41-50$ years $(42 \%)$. The modal age of the household energy decision-maker was 46 years. Forty five per cent of respondents had obtained tertiary education. The mean household size of the respondents was four with 49 percent of the respondents being self-employed while 39.8 percent were civil servants.

\section{Cooking energy pairings of households}

The combination of fuel type in families was essential in predicting how families rose up the energy ladder. The study analysed energy trends across the various residential zones in the Kumasi Metropolis. This section provides a synopsis of the pattern of energy choice in each residential zone. Items examined in this section comprised the main energy choice, backup energy choice, and energy pairings in each area. The analysis was done in two forms: aggregation of all residential zones and a split into each residential zone. Table 3 shows the energy pairings in the Kumasi Metropolitan area.

Table 3: Household cooking energy pairings in Kumasi Metropolitan Assembly

\begin{tabular}{lllcc}
\hline Main fuel & & Backup fuel & Frequency & Percent $(\%)$ \\
\hline Wood & $*$ & Charcoal & 16 & 3.9 \\
Charcoal & $*$ & Wood & 8 & 2.0 \\
Charcoal & $*$ & LPG & 113 & 27.9 \\
LPG & $*$ & Charcoal & 158 & 39.0 \\
LPG & $*$ & Kerosene & 4 & 1.0 \\
LPG & $*$ & Electricity & 83 & 20.5 \\
Electricity & $*$ & LPG & 23 & 5.7 \\
\hline Total & & 405 & 100.0 \\
\hline n=405 & & &
\end{tabular}

From Table 3, nearly $4 \%$ of the respondents who used wood as their primary fuel said they opted for charcoal as their backup when the distance they had to travel to get to the forest became too long. Also, respondents said that in the raining season, bushes get wet and it becomes impossible to use firewood, as such they opted for charcoal as a backup fuel. Furthermore, out of the total number of respondents who used charcoal as the primary fuel, 6.6 percent also chose wood as a backup fuel since it had a zero cost of acquisition for them.

However, $93.4 \%$ of respondents who used charcoal as their primary energy opted for LPG as a backup fuel. These respondents asserted that they mostly became hard pressed for time, and they returned home late. Using charcoal might delay the preparation of meals; hence, they used the gas cylinder as a backup fuel which made cooking more comfortable and faster. Other reasons given for the usage of LPG as a backup fuel was that it helped in the preparation of breakfast meals when one was in a hurry.

The result was further disaggregated to reveal energy pairings in each residential zone. The aim was to make a comparative analysis as to how each residential area responded to the energy ladder and energy stack assumptions. Table 4 shows energy parings across the various residential zones.
From Table 4, the majority of households $(82.4 \%)$ within the high-density low-class area (HDLA) used charcoal as their primary energy choice with LPG and wood being backup fuels. Again, in the same residential area, about 14.8 percent used wood as primary energy choice with charcoal as a backup fuel while on the other hand a minority of them, 2.8 percent, used LPG as their main household fuel and charcoal as a backup fuel. The dominant use of charcoal in this residential area was due to the accessibility of the fuel on the one hand and its affordability on the other side.

According to the primary charcoal users, they could buy at least GHC2 and would be able to cook a meal. Other reasons given by respondents were that they did not receive their income on regular bases and found it challenging to buy LPG which was not less than GHC20 per month. Furthermore, respondents commented on the irregular supply of LPG in and around the area that made it difficult to opt for it. Moreover, they added that price volatility associated with the amount of gas also deterred them from its usage.

On the issue of stove characteristics, the majority $(97 \%)$ of respondents within the HDLA asserted that they preferred to use coal pot. Reasons per their choice suggested that the coal pot was safer and with limited risk as compared to gas. It 
Table 4: Disaggregated household cooking energy pairings across the four (4) Residential Zones

\begin{tabular}{|c|c|c|c|c|}
\hline \multicolumn{5}{|c|}{ Residential household energy pairings } \\
\hline Main fuel & & Backup fuel & Frequency $(\mathbf{N})$ & Percent (\%) \\
\hline \multicolumn{5}{|l|}{$H D L A$} \\
\hline Charcoal & $*$ & LPG & 81 & 75.0 \\
\hline Wood & $*$ & Charcoal & 16 & 14.8 \\
\hline Charcoal & $*$ & Wood & 8 & 7.4 \\
\hline LPG & $*$ & Charcoal & 3 & 2.8 \\
\hline Total & & & 108 & 100.0 \\
\hline \multicolumn{5}{|l|}{ HDMA } \\
\hline LPG & $*$ & Charcoal & 76 & 70.4 \\
\hline Charcoal & $*$ & LPG & 18 & 16.7 \\
\hline LPG & $*$ & Electricity & 12 & 11.1 \\
\hline LPG & $*$ & Kerosene & 2 & 1.8 \\
\hline Total & & & 108 & 100.0 \\
\hline \multicolumn{5}{|l|}{ LDHA } \\
\hline LPG & $*$ & Electricity & 60 & 72.3 \\
\hline Electricity & * & LPG & 23 & 27.7 \\
\hline Total & & & 83 & 100.0 \\
\hline \multicolumn{5}{|l|}{ MDMA } \\
\hline LPG & $*$ & Charcoal & 79 & 74.5 \\
\hline Charcoal & $*$ & LPG & 14 & 13.2 \\
\hline LPG & $*$ & Electricity & 11 & 10.4 \\
\hline LPG & $*$ & Kerosene & 2 & 1.9 \\
\hline Total & & & 106 & 100.0 \\
\hline
\end{tabular}

Source: Field survey, 2015

$\mathrm{N}<405$ because of non- response

was revealed that respondents in the high-density low-class area found it difficult to climb the ladder since the dominant fuel mixes were both traditional and modern. The findings are in line with Davis's (1998) assertion that changes in fuel choice is not a smooth transition from biomass to commercial fuels but a continual switching between the two different combinations (traditional and modern fuels).

Findings from the high-density mediumclass area (HDMA) show that almost all the residents were stacking in the choice of household energy; they combined both traditional and modern fuels at the same time. The study found that the majority of households (70.4\%) who used LPG as their primary energy choice preferred to use charcoal as a backup fuel. However, 11.1percent similarly used LPG as their primary energy choice with electricity as a backup fuel while a minority of respondents $(1.8 \%)$ used kerosene as a backup fuel with LPG as their primary energy. The dominant use of LPG in this residential area was due to the accessibility and affordability of the fuel to these respondents.

Within the low-density high-class area
(LDHA), the majority of households (72.3\%) combined LPG with electricity as their primary and backup fuel respectively. On the other hand, 27.7 percent of the respondents used electricity as their primary fuel and LPG as their backup fuel. Respondents from this zone were high-income earners whose fuel combinations were both modern types. Here, households were interested in convenience and accessibility as most respondents justified their choice of fuel (LPG and electricity) as healthier, easily acquired and released minimum carbon. The results indicated that respondents with the high economic class were conservative about the environment as compared to those of the low level. Here, respondents' choice of fuel was in line with the energy ladder hypothesis where households completely stopped the use of biomass, charcoal and wood.

Also, the majority of respondents (74.5\%) in the medium density medium class (MDMA) category used LPG as their main fuel and Charcoal as a backup fuel. The study further revealed that a little over 13 percent of respondents in the medium 
density medium class area used charcoal as their main fuel and opted for LPG as a backup fuel. This is an indication that the household energy mix was more of stacking since households combined both the modern and traditional fuels in the choice of fuel. However, the predominant use of modern fuel (i.e., LPG) was a reflection of higher ability to pay for it, as compared to the other two zones.

\section{Use of traditional biomas fuels against liquefied petroleum gas}

Respondents who used charcoal explained that the coal pot was safer and risk free as compared to gas. Furthermore, they noted that price volatility associated with the supply of gas also deterred them from its usage. A woman expressed concern about the explosive nature of gas cylinders in the highdensity residential area by saying that:

"Just this year alone, two houses got burnt in this area. The first happened when a man left his stove on after preparing a meal, little did the wife know that the gas was still on and the second occurred when a young lady got burnt with her daughter when preparing a meal but failed to check her leaking gas tube".

Respondents were also asked about the benefits derived from the use of wood and charcoal as identified in the study. Also purported by respondents, wood and charcoal were good fuel types which helped households to prepare all kinds of meals with ease. Also, food cooked with charcoal or wood tasted differently from food prepared using gas stove.

Another participant pointed out that;

"Charcoal is medicinal and helps in preserving food, I use it mostly when my soup is getting spoilt, it also gives a different flavour to smoked fish when grilled on a coal pot as compared to the gas cylinder. Furthermore, preparing banku on a coal pot is much easier than doing it on a gas stove".

\section{Role of income in residential energy choice decision}

According to the Energy Ladder model, economic status drives energy switch. Core to the financial situation is the element of income, which is a major and a sufficient condition for an individual's choice of energy. Based on this theoretical basis, a test analysis was done to examine how energy choice differed among households with varying incomes. The choice of test done was informed by the normality of income distribution in each residential zone. In residential zones, where income distribution approximated normality, the independent samples t-test was used to examine differences in household fuel types.

However, in residential zones where income was skewed, the Kruskal Wallis test was used to explore whether or not income differed across the different residential zones. A similar test analysis was done to examine whether or not the income difference in the residential zones had further implications on peoples' energy choice decisions. This therefore juxtaposed that the analysis was done in two forms: income difference in the residential zones and income difference across fuel/energy types.

\section{Income distribution in residential zones}

This section examined the income level of respondents in each residential zone. This was done to determine the number of respondents who earned more or less than the overall zones median income of $\mathbb{C} 990$ in each residential zone. If respondents earned more income, then it should reflect in their energy choice decisions as purported by the energy ladder model. Table 5 shows the income distribution of residents in various residential zones.

Table 5 shows that all respondents in the low-density high-class area had incomes of more than $\mathbb{C} 990$ as compared to 48 out of 108 respondents from medium-density medium class areas. However, 85 out of 108 respondents from the high-density lowclass area had incomes lower than or equal to the median income of $\mathbb{C} 990$ per month. The median test showed that incomes differed across residential zones. The claim was valid under both one percent and five percent levels of significance.

Table 5: Income distribution by residential zones

\begin{tabular}{lcccc}
\hline Frequency & LDHA & MDMA & HDMA & HDLA \\
\hline$>$ Median & 83 & 48 & 43 & 23 \\
$<=$ Median & 0 & 60 & 63 & 85 \\
\hline Total & 83 & 108 & 106 & 108 \\
\hline
\end{tabular}

Median=990, $\mathrm{x}^{\wedge} 2=123.492, \mathrm{df}=3, \square=0.05, \mathrm{p}$-value $=.000$

Source: Field survey, 2015 
Table 6: Income distribution by main fuel type in high-density low-class areas

\begin{tabular}{lccc}
\hline Frequency & LPG & Charcoal & Wood \\
\hline$>$ Median & 3 & 50 & - \\
$<=$ Median & - & 39 & 16 \\
\hline Total & 3 & 89 & 16 \\
\hline
\end{tabular}

Median $=600, \mathrm{x}^{\wedge} 2=20.329, \mathrm{df}=2, \square=0.05, \mathrm{p}$-value $=.000$

Source: Field survey, 2015

Income and energy choice decisions in HDLA

The income distribution about the median income in the high density low class areas was investigated and the distribution of main fuel type by the position in relation to the median income is shown in Table 6.

The median test showed that most of the respondents who used LPG and charcoal had incomes more than the median income of $C 600$ per month. Concerning LPG users, all respondents had incomes of more than C600. Similarly, about 56 percent of respondents who used charcoal in this residential zone also had incomes more than the median income. However, all wood users in this zone had incomes lower than or equal to the median income. This is an indication that in the high-density low-class area, the majority of charcoal and LPG users received higher incomes than wood users.

Income and energy choice decisions in HDMA

The study examined the difference in income across the various energy choices within the high-density medium class area. The energy sources mainly used in this residential category were charcoal and LPG. Table 7 illustrates the detailed results.

Table 7: Income distribution across main fuel types

\begin{tabular}{llcc}
\hline Fuel type & $\mathrm{N}$ & Mean & Std. deviation \\
\hline Charcoal & 18 & 865.556 & 285.002 \\
LPG & 90 & 895.333 & 361.430 \\
\hline F=9.495, p-value $=.743$ & & & \\
Source: Field survey, 2015 & & &
\end{tabular}

The mean income of charcoal users was C865 as compared to LPG users with a higher income of $\mathbb{C} 895$. It could be seen from the results that LPG users, on the whole, received a higher income than charcoal users. But as to whether this difference is significant to predict that all LPG users in the residential category have higher incomes than charcoal users was decided with the independent samples t-test. The results of this test indicated that there was no significant difference in income between charcoal and LPG users, $\mathrm{t}=$ $.33, \mathrm{p}=.743$. These results suggest that individuals who used charcoal $(\mathrm{M}=865.6 ; \mathrm{SD}=285)$ earned no less income than LPG users $(\mathrm{M}=895.3$; $\mathrm{SD}=$ 361.43) in this zone.

The study revealed that income played no significant role in household energy choice of respondents in the high-density medium class area. Users of LPG and charcoal had barely the same income, yet their preferences encompassed biomass and modern fuels. In more nuanced formulations of energy transition theory, Schlag and Zuzarte (2008) suggest that the scenario of households switching from exclusive use of one type of fuel to exclusive use of another is overly simplistic. Several factors, such as accessibility to the fuel source and preference, played significant roles in respondents' choice of fuel. Hence income is only a necessary but not a sufficient condition for energy choice. Sufficiency factors such as accessibility and taste must be considered as was suggested by most respondents in this area.

Income and energy choice decisions in medium density medium class areas (MDMA)

The study examined the differences in income across the various energy choices within the medium density medium class area. The cooking energy sources mainly used in this residential category were charcoal and LPG. The distribution of income within this residential status was approximately normal (Skewness $=-.026$ ). Hence, a parametric test procedure was used to carry out the investigation into the differences in the energy types. Table 8 shows the income distribution by main fuel type in medium density medium class areas. 
Table 8: Income distribution across the main fuel types

\begin{tabular}{lccc}
\hline Fuel type & $\mathrm{N}$ & Mean & Std. deviation \\
\hline Charcoal & 14 & 444.286 & 356.925 \\
LPG & 92 & 884.456 & 362.353 \\
\hline
\end{tabular}

$\mathrm{F}=.376, \mathrm{p}$-value $=.000 . \quad$ Source: Field survey, 2015

The mean income of charcoal users was C444.286 as compared to LPG users with a higher income of $\mathbb{C} 884.456$. It could be seen from the results that LPG users earned higher incomes than charcoal users. Indeed, the results revealed that in this residential zone the difference in income is significant to predict that all LPG users in the residential category had higher incomes than charcoal users. It further implies that higher income earners in the medium density medium class residential area preferred to use LPG than charcoal. Income and energy choice decisions in low-density high-class areas
The study examined the differences in incomes across the various energy choices within the low-density high-class area. The distribution of income within this zone was not approximately normal (skewness $=1.049)$, hence a non-parametric test procedure was needed to carry out investigations into the differences in energy types. The study, therefore, used the Mann-Whitney Test to examine differences in income within this zone. The energy used primarily in this residential category was LPG and electricity. Table 9 presents the income distribution by the energy source.

Table 9: Income distribution by main energy types

\begin{tabular}{llc}
\hline Fuel type & $\mathrm{N}$ & Mean Rank \\
\hline LPG & 60 & 39.79 \\
Electricity & 23 & 47.76 \\
\hline
\end{tabular}

Median $=2300, \mathrm{x}^{\wedge} 2=557.500,, \square=0.05, \mathrm{p}$-value $=.176$

The median test further showed that most of the respondents who used electricity and LPG had an average income (median) of $\mathbb{C} 2300$ per month. The results of the Mann- Whitney U test indicated that there was no significant difference in salary for LPG and electricity users, $p=.176$. Hence, the income difference between the preferences of modern fuel was not substantial. Conclusively, the rich preferred to use either electricity or LPG as their primary cooking fuel. Most respondents in this zone had higher incomes relative to other residential areas which influenced their choice of modern fuels.

The results indicate that within this zone, as income increased, respondents were indifferent about their choice of modern fuel. The low-density high-class residential area portrayed that income was a sufficient condition for determining one's energy choice since all respondents $(100 \%)$ in this area used LPG or electricity as their primary cooking fuel. This finding contradicts Barnes and Qian (1992) who used an actual survey of urban household energy consumption in developing countries and found that as income increases, fuelwood does not disappear entirely as households continue to use firewood.
Socio-economic factors that influence fuel choice

This section examined the socio-economic factors that influenced fuel choice. Operationally, socio-economic factors comprised all households' demographic characteristics and other economic factors. Income was not included in the model since it had been addressed in earlier discussions. Variables examined were age, household size, education, occupation, time for collection, household expenditure and price of fuel.

The study used multinomial logit analysis as the test procedure to examine socio-economic factors that influenced fuel use. The dependent variable (energy choice) was a categorical variable with five categories. These categories are firewood, charcoal, kerosene, LPG and electricity. The base (reference) fuel is LPG. Most of the variables used in this model were statistically significant. Coefficients, odds ratios, and standard errors were reported respectively on factors that influenced energy choice. Table 10 presents a multinomial logit of fuel choice estimation results.

The coefficient on age is positive for wood, charcoal, and electricity. However, only wood usage is significantly related to age. This means that a one 
(1) percent increase in the proportion of age will increase the probability of using wood by 0.1051 percent. Households with aged respondents located in the low-class residential areas were more likely to use traditional fuels compared to families in highclass residential areas; this is probably because of inadequate education on the energy use in these low-class areas or income differences.

The coefficient on household size is positive for wood and charcoal. This means that a one (1) percent increase in the proportion of household size will lead to 1.2692 and 0.7707 percent increase in the usage of wood and charcoal respectively. The finding indicates that residents with larger household sizes were more likely to use traditional fuels relative to smaller households. This result is consistent with Mekonnen and Kohlin (2009) who found similar results in Ethiopia where families with more members were more likely to use charcoal and firewood and less possible to use kerosene.

Table 10: Multinomial logistic regression for fuel types

\begin{tabular}{|c|c|c|c|}
\hline \multirow[b]{2}{*}{ Variables } & \multicolumn{3}{|c|}{ Fuel types } \\
\hline & Wood & Charcoal & Electricity \\
\hline \multirow[t]{3}{*}{ Age of respondent } & .1051 & .0024 & .0448 \\
\hline & 1.110 & 1.002 & 1.045 \\
\hline & $(.0543)^{* * *}$ & $(.0166)$ & $(.0392)$ \\
\hline \multirow[t]{3}{*}{ Household size } & 1.2692 & .7707 & -.3604 \\
\hline & 3.558 & 2.161 & .697 \\
\hline & $(.5173)^{* *}$ & $(.1633)^{* * *}$ & $(.3075)$ \\
\hline \multirow[t]{3}{*}{ Educational status } & -1.2005 & -1.3466 & $(-.1836)$ \\
\hline & .301 & .2601 & .832 \\
\hline & $(.4896)^{* *}$ & $(.2274)^{* * *}$ & $(.6325)$ \\
\hline \multirow[t]{3}{*}{ Occupation } & -.1534 & .5920 & -.6058273 \\
\hline & .858 & 1.807 & .545 \\
\hline & $(.7719)$ & $(.3787)$ & $(.5732)$ \\
\hline \multirow[t]{3}{*}{ Monthly Expenditure } & -.0254 & -.0022 & .0015 \\
\hline & .975 & .998 & 1.00 \\
\hline & $(.0066) * * *$ & $(.0005)^{* * *}$ & $(.0003)^{* * *}$ \\
\hline \multirow[t]{3}{*}{ Collection time } & -11.4498 & .0530 & .1687 \\
\hline & .000 & 1.054 & 1.183 \\
\hline & $(1.5214)^{* * *}$ & $(.0239)^{* *}$ & $(.0424)^{* * *}$ \\
\hline \multirow[t]{3}{*}{ Price of fuel } & .1442 & $(-.0120)$ & -.0647 \\
\hline & 1.155 & .988 & .937 \\
\hline & $(.05612)^{* *}$ & .0438 & $(.0336)^{*}$ \\
\hline \multirow[t]{3}{*}{ Constant } & 30.6240 & $(.7077)$ & -7.3555 \\
\hline & $1.99 \mathrm{e}+13$ & 2.029 & .000 \\
\hline & $(6.5246)$ & $(1.3733)$ & $(2.7099)$ \\
\hline Pseudo & 0.5496 & & \\
\hline Wald test & 316.06 & & \\
\hline
\end{tabular}

Concerning firewood, the coefficient for education is negative for electricity but not statistically significant, while negative and statistically significant for wood and charcoal. A unit increase in educational level will lead to 1.2005 and 1.3466 percent decrease in the usage of wood and charcoal. This may imply that household decisionmakers with higher education were more likely to use LPG and electricity than firewood. This result is consistent with that reported by Pundo and Fraser (2003) and Wuyuan et al. (2003) who found that the level of education improves knowledge of fuel attributes, tastes, and preferences for better fuels.

In economic theory, it is hypothesized that the demand for a good is inversely related to the price of that good and this necessitates that the 
price elasticity of application should be negative. A 1 percent increase in the cost of electricity will decrease the probability of consuming power by 0.0647 percent. This result is consistent with that of Mekonnen and Kohlin (2009) and Schlag and Zuzarte (2008) who found that fuel price hurt fuel substitution.

Relative to firewood, the coefficients of distance are statistically significant and negative for wood only. A 1 percent increase in the collection time will decrease the probability of using wood by 11.4498 percent. The result is consistent with that of Albebaw (2007) who also found a negative coefficient between wood consumption and distance. This implies that the farther the distance from the fuel source, the less likely households were willing to use the fuel. Distance to the fuel source, possibly, captures aspects on fuel security, availability and accessibility of fuels by families. Besides, households may perceive distance as an additional cost to the market fuel price.

The coefficients on expenditure (-.0254) and (-.0022) are negative for wood and charcoal respectively. This means that a 1 percent increase in the proportion of income will decrease the probability of using wood and charcoal by 0.0254 and 0.0022 percent. This says that the affordability of modern fuels improves as incomes increased.

\section{Conclusions and Policy Implications}

The present study evaluated the household energy choice decisions within the Kumasi Metropolis. It was observed that a large proportion of the population used traditional biomass fuels for cooking. Besides, people preferred gas over biomass fuels for being efficient and environmentally friendly. Also, governments over the years have promoted the use of modern fuels, and as such more fuel stations were providing these services to households and the general public. However the use of gas by some families was limited, due to its unavailability. Communities such as Ayigya Zongo and Ampabame had to travel longer distances before they could get access to LPG. In areas with low forest cover and an exponentially rising population, efforts should be made to decrease the per-capita

\section{References}

Agbonlahor, O. (2015). The effect of urban household lifestyle changes onenergy demand in China. USAEE Dialogue, 23(2) (May 2015). Agency and Organization for Economic Cooperation consumption of wood fuels since it poses a danger to the environment. Hence, places like Ampabame and Aparade should be of prime focus in terms of reducing wood fuel consumption irrespective of the numerous reasons that influenced their choice since it poses a danger to the environment.

An assessment focusing on the role of income in private energy choice decisions revealed a contextual variation where income was seen as a sole determinant for a particular fuel type did not hold for all residential zones. For low-density highclass areas, residents travelled far to get a cleaner energy fuel, knowing that the opportunity cost of their choice was severe environmental problems. The reasons that influenced the decision of energy in residential zones were context specific. High-class suburban dwellers prioritized their health while low-class residential areas placed importance on affordability. It was also clear from the study that income was not the sole determinant of households' energy choice decisions. Instead, other socioeconomic factors (education, occupation, household size, collection time), as well as government policy, played a critical role in the choice of fuel.

The Energy Commission should continuously deepen the campaign on the use of improved fuel and gas stoves as a means of ensuring the full actualization of the Sustainable Development Goal seven (7): affordable and cleaner energy. Besides, there should be a continuous national campaign on enhanced ventilation of the cooking area and promotion of modern fuels by developing reliable energy distribution systems with adequate and dependable refuelling units.

Furthermore, uninterrupted public education on the harmful effects of unclean sources of household energy, as part of any energy sector reform, is highly recommended for achieving development, increased productivity and reduced deforestation as well as improved human health. Lastly, Government should pay much attention to affordability; reducing taxes placed on modern fuels and not only on availability, since that is the most efficient way of reducing the volume of biomass fuel use and preventing acute respiratory diseases.

and Development.

Akabah, E.M. (1990). Real incomes and the consumption of wood fuels in Ghana: an analysis of recent trends, Energy Economics 12 (3), pp. 227-231. 
Albebaw, D. (2007). Household determinants of fuelwood choice in urban Ethiopia: the Case study of Jimma Town. Journal of Developing Areas, 41(1):117-126. An alternative. Technological Forecasting \& Social Change 68(2001) 173-193.

Anenberg S. (2012). Technology: Clean stoves benefit climate and health. Nature. 490: 343.

Arnold, W., Ruf, T., \& Kuntz, R. (2006). Seasonal adjustment of energy budget in a large wild mammal, the Przewalski horse (Equus ferus przewalskii) II. Energy expenditure. Journal of Experimental Biology, 209(22), 4566-4573.

Asante, F.A., Addoquaye-Tagoe, C.A. and Clottey, E.A. (2006). Ghana Gender and Energy National Paper Draft, National Paper prepared for the 14th Session of the UN. Commission on Sustainable Development, Paper commissioned by ENERGIA.

Barnes, D. F., \& Floor, W. M. (1996). Rural energy in developing countries: a challenge for economic development1. Annual review of energy and the environment, 21.

Barnes, D. F., \& Qian, L. (1992). Urban interfuel substitution, energy use, and equity in developing countries: some preliminary results. The World Bank.

Barnes, F., Openshaw, K., Smith, K., \& van der Plas, R., (1993). The design and diffusion of improved cooking stoves. In World Bank Research Observer, 8(2)119-141.

Burdens", in Marcotullio, P. \& McGranahan, G (eds) Scaling the Urban Environmental Challenge: From local to global and back, London: Earth scan.

Bowling, A. (2009). Research methods in health : investigating health and health services. McGraw-Hill Education.

Campbell, B. M., Vermeulen, S. J., Mangono, J. J., \& Mabugu, R. (2003). The energy transition in action: urban domestic fuel choices in a changing Zimbabwe. Energy Policy, 31(6), 553-562.

Cartographic Unit, (2015). Data Unit of Geography and Regional Planning, University of Cape Coast. Cape Coast.

Cochran, W.G. (1977) Sampling Techniques. 3rd Edition, John Wiley and Sons, New York.

Davis, M. (1998). Rural household energy consumption: the effects of access to electricity - evidence from South Africa. Energy Policy, 26(3), 207-217.

Durkheim (1984). The division of labour in society. Free Press.

Dutta, S. (2005). Energy as a key variable in eradicating extreme poverty and hunger: A gender and energy perspective on empirical evidence. On MDG\# 1. Noida, Ghaziabad:ENERGIA International network on gender and energy.ESMAP (2003). Household Energy Use in Developing Countries: A Multicounty Study. Washington, DC: World Bank.

GSS (2010). 2010 Population and Housing Census. Accra: Ghana Statistical Service. Heltberg, R., Arndt, T. C., \& Sekhar, N. U. (2000). Fuel wood consumption and forest degradation: A household model for domestic energy substitution in rural India. Land Economics, 76(2): 213-232.

Heltberg, R. (2004). Fuel switching: Evidence from eight developing countries. Energy Economics, 26(5), 869-887.

Hiemstra-Van der Horst, G., \& Hovorka, A. J. (2008). Reassessing the "energy ladder": Household energy use in Maun, Botswana. Energy Policy, 36(9), 33333344.

Hoffmeyer-Zlotnik, J.H.P. (2003) New Sampling Designs and the Quality of Data, Developments in Applied Statistics, Metodološki zvezki 19, Ljubljana.

International Energy Agency (IEA) (2010). World Energy Outlook 2010, Paris: International Energy.

Jebaraji, S., \& Iniyan, S. (2006). A review of energy models. Renewable and sustainable energy reviews, 10(4), 281-311.

Joon, V., Chandra, A., \& Bhattacharya, M. (2009). Household energy consumption pattern and socio-cultural dimensions associated with it: A case study of rural Haryana, India. Biomass and Bioenergy, 33(11), 1509-1512.

Kaale, B.K. (1990). Traditional fuels, in J. Pasztor, and L.A. Kristoferson, (eds.), Bioenergy and the Environmental. Oxford, U.K.: Westview Press.

Kanagawa, M., \& Nakata, T. (2007). Analysis of the energy access improvement and its socio-economic impacts in rural 
areas of developing countries. Ecological economics, 62(2), 319-329.

KMA(2016). The composite budget of the Kumasi Metropolitan Assembly for the 2016 fiscal year. Kumasi Metropolitan Assembly.

Krejcie, R. V. \& Morgan, D. W. (1970). Determining sample size for research activities. Educational and Psychological Measurement, 30, 607-610.

Leach, G. (1992). The energy transition. Energy Policy 20(2):116-123.

Macht, C., Axinn, W. \& Ghimire, D. (2007). Household energy consumption: Community context and the fuelwood Transition. Population Studies Center, University of Michigan.

Martins, J. (2005). The impact of the use of energy sources on the quality of life of poor communities. Social Indicators Research, 72(3), 373-402.

Masera, O., Saatkamp, B., \& Kammen, D. (2000). From linear fuel switching to multiple cooking strategies: A critique and alternative to the Energy Ladder Model. World Development, 28 (12), 2083-2103.

Masera, O. R., \& Navia, J. (1997). Fuel switching or multiple cooking fuels? Understanding inter-fuel substitution patterns in rural Mexican households. Biomass and Bioenergy, 12(5), 347-361.

McGranahan, G. (2007). Urban transitions and the spatial displacement of environmental burdens. Scaling urban environmental challenges: from local to global and back, 18-44.

Mekonnen, A. and Kohlin, G. (2009). Determinants of household fuel choice in major cities in Ethiopia. Working Papers in Economics No 399, School of Business, Economics and Law, University of Gothenburg.

Milukas, M. V. (1993). Energy for secondary cities: the case of Nakuru, Kenya. Energy Policy, 21(5), 543-558.

Ministry of Energy (2010). Energy Commission of Ghana. Ghana.

Munasinghe, M., (1999). Is environmental degradation an inevitable consequence of economic growth: Tunnelling through the environmental Kuznets curve? Ecological Economics, 29, 89-109.

Murphy, J. T. (2001). Making the energy transition in rural East Africa: Is leapfrogging an alternative? Technological Forecasting and Social Change, 68(2), 173-193.

Obeng, G. Y., Mensah, E., Ashiagbor, G., Boahen, O. \& Sweeney, D. J. (2017). Watching the smoke rise up: Thermal efficiency, pollutant emissions and global warming impact of three biomass cook stoves in Ghana. Energies, 10, 641.

OECD \& IEA, (2010). $\mathrm{CO}_{2}$ Emissions from Fuel Combustion: Highlights

of the energy ladder hypothesis. Resources and Energy 9 (4):347-361.

Ouedraogo, B. (2006). Household energy preferences for cooking in urban Ouagadougou, Burkina Faso. Energy policy, 34(18), 3787-3795.

Pachauri, S. (2011). Reaching an international consensus on defining modern energy access. Current Opinion in Environmental Sustainability, 3(4), 235240.Paris, Organization for Economic Co- operation and Development \& International Energy Agency, 2010:130.

PREDAS (Programme for the Promotion of Household and Alternative Energy sources in the Sahel) (2009). Women and household energy in Sahelian countries: A Boiling Point special supplement from PREDAS. Boiling Point (56). Retrieved from http://www.hedon.info/docs/BP56 PREDAS.pdf.

Prentice, R. L., Mossavar-Rahmani, Y., Huang, Y., Van Horn, L., Beresford, S. A., Caan, B., \& Thomson, C. (2011). Evaluation and comparison of food records, recalls, and frequencies for energy and protein assessment by using recovery biomarkers. American journal of epidemiology, 174(5), 591-603.

Pundo, M. O. \& Fraser, G. C. G. (2003). Multinomial logit analysis of household cooking fuel choice in rural Kenya: A case of Kisumu District. Contributed paper presented at the $41^{\text {st }}$ Annual Conference of the Agricultural Economic Association of South Africa (AEASA), October2-4, 2003, Pretoria, South Africa.

Reddy, A. K., \& Reddy, B. S. (1994). Substitution of energy carriers for cooking in Bangalore. Energy, 19(5), 561-571. Retrieved November 8, 2007 from http:// www.euro.who.int/Document/E87950. 
pdf.

Schlag, N. \& Zuzarte, F. (2008). Market barriers to clean cooking fuels in Sub-Saharan Africa: A review of literature. Working Paper, Stockholm Environment Institute, Sweden.

Singh, G., Nouhou, S. A., \& Sokona, M. Y. (2015). Ghana renewables readiness assessment. International Renewable Energy Agency. Abu Dhabi, United Arab Emirates. Socioeconomic impacts in rural areas of developing countries. Ecol. Econ. 62, (2), 319.

Tipple, G. (1984). Household size and composition and implications for housing $\mathrm{n}$ e e d in Kumasi, Ghana: a research note, Planning Outlook, 27:2, 98-105, DOI: $10.1080 / 00320718408711726$. United Nations (UN) (2005). Designing Household Survey Samples: Practical Guidelines, Department of Economic and Social Affairs, Statistics Division, Studies in Methods, Series F No.98, UN, New York.
World Health Organisation (WHO) (2010). WHO air quality guidelines global update? Report on a working group meeting, Bonn Germany. Geneva: World Health Organisation.

Wuyuan, P., Zerriffi, H., \& Jihua, P. (2008). Household level fuel switching in rural Hubei. Stanford University. The Program on Energy and Sustainable Development (PESD), Stanford, USA. 